\title{
Reduction of the systemic inflammatory induced by acute cerebral infarction through ultra-early thrombolytic therapy
}

\author{
LICHAO YE, RUOWEI CAI, MEILI YANG, JIAQIANG QIAN and ZHILIN HONG
}

Department of Neurology, The Second Affiliated Hospital of Fujian Medical University, Quanzhou, Fujian 362000, P.R. China

Received September 14, 2014; Accepted June 26, 2015

DOI: $10.3892 /$ etm.2015.2672

\begin{abstract}
Acute ischemic stroke induces systemic inflammation, exhibited as changes in body temperature, white blood cell counts and C-reactive protein (CRP) levels. The aim of the present study was to observe the effects of intravenous thrombolytic therapy on inflammatory indices in order to investigate the hypothesis that post-stroke systemic inflammatory response occurs in response to the necrosis of brain tissues. In this study, 62 patients with acute cerebral infarction and indications for intravenous thrombolysis were divided into three groups on the basis of their treatment and response: Successful thrombolysis $(n=36)$, failed thrombolysis $(n=12)$ and control $(n=14)$ groups. The body temperature, white blood cell counts and highsensitivity (hs)-CRP levels were recorded pre-treatment and on post-stroke days 1, 3, 5 and 7. Spearman's correlation analysis showed that the pre-treatment National Institutes of Health Stroke Scale (NIHSS) score positively correlated with body temperature, white blood cell count and hs-CRP levels. On day 3 of effective intravenous thrombolysis, the body temperature and white blood cell were decreased and on days 3 and 5, the serum levels of hs-CRP were reduced compared with those in the failed thrombolysis and control groups. The results indicate that the systemic inflammatory response following acute cerebral infarction was mainly caused by ischemic injury of local brain tissue; the more serious the stroke, the stronger the inflammatory response. Ultra-early thrombolytic therapy may inhibit the necrosis of brain tissue and thereby reduce the inflammatory response.
\end{abstract}

\section{Introduction}

The inflammatory process plays an important role in the occurrence and development of ischemic cerebrovascular disease. Evidence has shown that with the incidence of isch-

Correspondence to: Dr Ruowei Cai, Department of Neurology, The Second Affiliated Hospital of Fujian Medical University, 34 Zhonghsan North Road, Quanzhou, Fujian 362000, P.R. China E-mail: ruoweicai@163.com

Key words: infarction, inflammation, thrombolytic therapy, body temperature, C-reactive protein, white blood cell emia, an inflammatory response also occurs and participates in the injury and repair of brain tissues. The inflammatory cascade reaction following cerebral infarction is an important pathophysiological mechanism of ischemic stroke (1-3). The acute phase of the post-stroke inflammatory response is a reflective and non-specific systemic inflammatory response, accompanied by the accumulation of inflammatory cells, the release of inflammatory cytokines, the upregulation of leukocyte adhesion molecules, and the migration of macrophages and neutrophils to areas of tissue damage. Furthermore, some peripheral inflammatory indicators also change significantly, for example, white blood cell counts increase, and serum interleukin-6 and C-reactive protein (CRP) levels also increase (4-6). Bacterial or viral infections can induce ischemic stroke; furthermore, stroke, especially a serious stroke, is often complicated by pulmonary or urinary tract infections. Bacterial infection is likely to exacerbate the inflammatory response and increase brain tissue damage. Studies have confirmed that infection and fever have a significant correlation with a poor prognosis for stroke $(7,8)$. Prevention and treatment of bacterial infections, lowering the body temperature and controlling the inflammatory response have become treatment strategies for the acute phase of ischemic stroke. However, so far, little is known about the causes of the early systemic inflammatory response in ischemic stroke, and about the dynamic changes of most inflammatory markers in the acute phase of stroke.

In this study, dynamic changes of inflammatory indicators, such as body temperature, peripheral blood leukocyte counts and serum high-sensitivity (hs)-CRP levels in patients with acute cerebral infarction were observed with the aim of assessing the following hypotheses: The post-stroke systemic inflammatory response mainly occurs because of the necrosis of brain tissue, rather than cryptogenic infection. Successful thrombolytic treatment may reduce the necrosis of brain tissue and the inflammatory response, resulting in an earlier return of the inflammatory indicators to their normal ranges.

\section{Materials and methods}

General information. In total, 62 patients with acute cerebral infarction and intravenous thrombolytic indications were admitted to the Department of Neurology of the Second Affiliated Hospital of Fujian Medical University (Quanzhou, China) from January 2009 to February 2013. The patients comprised 36 males and 26 females and ranged from 35 
to 79 years old (mean, $62 \pm 10.4$ years). The patients were divided into three groups according to their treatment and response: i) successful thrombolysis group $(n=36)$; following thrombolytic therapy, the reduction of National Institutes of Health Stroke Scale (NIHSS) score within $24 \mathrm{~h}$ was $\geq 4$. ii) failed thrombolysis group $(n=12)$; following thrombolytic therapy, the reduction of NIHSS score within $24 \mathrm{~h}$ was $<4$; iii) control group $(n=14)$; no thrombolysis was performed, and only conventional antiplatelet or anticoagulant therapy was applied. Intravenous thrombolysis was administered within $3.0 \mathrm{~h}$ of stroke incidence in 30 patients, and within $3.0-4.5 \mathrm{~h}$ in 18 cases. This study was conducted in accordance with the Declaration of Helsinki and with approval from the Ethics Committee of Fujian Medical University. Written informed consent was obtained from all participants.

Enrollment standards. The inclusion criteria were as follows: i) aged 18-80 years; ii) signs of brain dysfunction persisted for $>1 \mathrm{~h}$, and the NIHSS score of nerve function was $\geq 4$ points; iii) stroke incidence was $<4.5 \mathrm{~h}$ ago; iv) blood pressure $<180 / 100 \mathrm{mmHg}$; v) brain computed tomography (CT) excluded intracranial hemorrhage, and no imaging changes indicative of acute cerebral infarction were observed; iv) if the patients and their families agreed to thrombolytic therapy, they were required to sign an informed consent form, otherwise they were treated with conventional therapy.

Exclusion criteria. The exclusion criteria were as follows: Intracranial hemorrhage, including secondary hemorrhage; already existing post-stroke infectious diseases; trauma and vascular events occurring 4 weeks before the stroke; chronic inflammation or malignancy; use of anti-inflammatory drugs, such as adrenal corticosteroids and non-steroidal anti-inflammatory agents (with the exception of aspirin); serious heart, liver or renal insufficiency.

Treatment. The patients in the successful thrombolysis group and failed thrombolysis group were treated intravenously with recombinant tissue-type plasminogen activator (alteplase/Actilyse; Boehringer Ingelheim, Ingelheim am Rhein, Germany) at a total dosage of $0.9 \mathrm{mg} / \mathrm{kg}$ body weight (maximum dosage, $90 \mathrm{mg}$ ); $10 \%$ of the dosage was intravenously injected in the first $1 \mathrm{~min}$, the rest was then intravenously injected uniformly over $60 \mathrm{~min}$. Aspirin $100 \mathrm{mg} /$ day or clopidogrel $75 \mathrm{mg} /$ day was given orally $24 \mathrm{~h}$ after the thrombolysis. Patients with atrial fibrillation were also given 4,000 IU low-molecular-weight heparin by abdominal subcutaneous injection twice/day $(9,10)$. Patients in the control group were treated orally with aspirin $100 \mathrm{mg} / \mathrm{day}$ or clopidogrel $75 \mathrm{mg} /$ day. Patients with atrial fibrillation were also given 4,000-5,000 IU low-molecular-weight heparin, by abdominal subcutaneous injection twice/day.

Laboratory tests. Routine cranial CT scanning was performed on enrollment and $24 \mathrm{~h}$ after the initiation of treatment. If the disease developed, CT scanning or cranial magnetic resonance imaging was performed in a timely manner. Daily measurements of body temperature were taken (axillary) at least 4 times, and the body temperature and daily maximum temperature were adopted as statistical data. The peripheral blood leukocyte counts were determined on the day of admission, and on days 1, 3, 5 and 7 after this, using conventional laboratory methods (normal range, $\left.4 \times 10^{9}-10 \times 10^{9} / 1\right)$. An immunoturbidimetry method (Wide Range C-Reactive Protein reagent; Siemens Healthcare Diagnostics Inc., Malvern, PA USA) was used for the determination of hs-CRP concentration (normal range, 1.4-11.0 mg/l).

Efficacy evaluation. The NIHSS was used to score the neurological deficits, and the scores were recorded on the day of admission and on days 1, 3, 5 and 7, respectively.

Statistical analysis. SPSS statistical software package version 11.0 (SPSS, Inc., Chicago, IL, USA) was used, and data are presented as the mean \pm standard deviation. Comparisons between groups are performed using a Student's t-test, while more than two groups were compared by one-way analysis of variance. Spearman's correlation analysis was applied to determine the correlation of two non-normally distributed variables. $\mathrm{P}<0.05$ was considered to indicate a statistically significant result.

\section{Results}

Baseline clinical characteristics. The baseline clinical characteristics, including gender, age, hypertension, diabetes, auricular fibrillation, stroke type and thrombolysis/treatment time in the three groups are shown in Table I. There were no significant differences between gender ratio and age among the three groups.

Inflammatory indicators in 62 cases of acute cerebral infarction. The inflammatory indicators, including body temperature, peripheral blood leukocyte count and hs-CRP in the 62 cases at various time-points are shown in Table II. Spearman's correlation analysis demonstrated that the NIHSS score of body temperature on post-stroke day 3 was significantly higher, as comparde with on the day of admission (prior to treatment $(\mathrm{P}<0.05)$. The NIHSS scores of peripheral blood leukocyte count on days 1 and 3 were significantly higher, as compared with on the day of admission $(\mathrm{P}<0.05)$. The NIHSS scores of hs-CRP on days 3,5 and 7 were significantly higher, as compared with on the day of admission $(\mathrm{P}<0.05)$.

Correlation analysis. The correlations of NIHSS score at admission and inflammatory indicators are shown in Table III. Spearman's correlation analysis demonstarted that the NIHSS score on the day of admission (prior to treatment) was significantly positively correlated with peripheral blood leukocyte count on post-stroke days 1 and $3(\mathrm{P}<0.05)$. It was also significantly positively correlated with the hs-CRP level on days 3, 5 and $7(\mathrm{P}<0.05)$. The NIHSS score was only significantly positively correlated with body temperature on day $3(\mathrm{P}<0.05)$.

Comparison of the three groups. No significant difference was observed among the three groups in the NIHSS scores of neurological deficit prior to treatment. However, the NIHSS score of the successful thrombolysis group was decreased significantly compared with that in the failed thrombolysis and 
Table I. Basic clinical characteristics of the 62 cases.

\begin{tabular}{|c|c|c|c|}
\hline Items & Successful thrombolysis (\%) & Failed thrombolysis (\%) & Control $(\%)$ \\
\hline Total number & 36 & 12 & 14 \\
\hline Male & $20(55.6)$ & $7(58.3)$ & $9(64.3)$ \\
\hline Female & $16(44.4)$ & $5(41.7)$ & $5(35.7)$ \\
\hline Age, mean $\pm \mathrm{SD}$ & $61.5 \pm 10.0$ & $62.8 \pm 11.2$ & $63.5 \pm 10.4$ \\
\hline Hypertensive disease & $12(33.3)$ & $7(58.3)$ & $8(57.14)$ \\
\hline Diabetics & $8(22.2)$ & $4(33.3)$ & $6(42.9)$ \\
\hline Auricular fibrillation & $10(27.8)$ & $6(50.0)$ & $6(42.9)$ \\
\hline \multicolumn{4}{|l|}{ Stroke type $(\text { TOAST) })^{a}$} \\
\hline Atherosclerosis & $6(16.7)$ & $2(16.7)$ & $2(14.3)$ \\
\hline Cardiogenic embolism & $10(27.8)$ & $6(50.0)$ & $6(42.9)$ \\
\hline Arterial embolism & $8(22.2)$ & $2(16.7)$ & $3(21.4)$ \\
\hline Other reason & $2(5.6)$ & 0 & 0 \\
\hline Unknown reason & $10(27.8)$ & $2(16.7)$ & $3(21.4)$ \\
\hline Thrombolysis/treatment within $0-3 \mathrm{~h}$ & $24(66.7)$ & $6(50.0)$ & $5(35.7)$ \\
\hline Thrombolysis/treatment within 3-4.5 h & $12(33.3)$ & $6(50.0)$ & $9(4.3)$ \\
\hline
\end{tabular}

${ }^{a}$ Based on trial of ORG 10172 in acute stroke therapy (TOAST) criteria (11). SD, standard deviation.

Table II. Inflammatory indicators in 62 cases of acute cerebral infarction.

\begin{tabular}{lccc}
\hline Time-point & $\begin{array}{c}\text { Body } \\
\text { temperature }\left({ }^{\circ} \mathrm{C}\right)\end{array}$ & $\begin{array}{c}\text { Leukocytes } \\
\left(\mathrm{x} 10^{9} / \mathrm{l}\right)\end{array}$ & $\begin{array}{c}\text { hs-CRP } \\
(\mathrm{mg} / \mathrm{l})\end{array}$ \\
\hline On admission & $36.5 \pm 0.5$ & $8.8 \pm 1.8$ & $8.9 \pm 6.8$ \\
Post-stroke day 1 & $36.6 \pm 0.6$ & $11.1 \pm 2.1^{\mathrm{a}}$ & $10.2 \pm 7.6$ \\
Post-stroke day 3 & $37.1 \pm 0.8^{\mathrm{a}}$ & $12.4 \pm 2.5^{\mathrm{a}}$ & $65.8 \pm 12.8^{\mathrm{a}}$ \\
Post-stroke day 5 & $36.8 \pm 0.5$ & $8.9 \pm 1.6$ & $38.2 \pm 9.9^{\mathrm{a}}$ \\
Post-stroke day 7 & $36.5 \pm 0.6$ & $8.6 \pm 1.5$ & $25.3 \pm 8.4^{\mathrm{a}}$ \\
\hline
\end{tabular}

${ }^{a} \mathrm{P}<0.05$, compared with on admission. hs-CRP, high-sensitivity C-reactive protein.

control groups on days 1 and $7(\mathrm{P}<0.001)$. The body temperature of the successful thrombolysis group was significantly lower than that in the other two groups on day $3(\mathrm{P}<0.005)$, with a significant reduction in the number of peripheral blood leukocytes $(\mathrm{P}<0.001)$. The level of hs-CRP was significantly reduced in the successful thrombolysis group on days 3 and 5, when compared with the failed thrombolysis and control groups ( $\mathrm{P}<0.001$; Table IV; Fig. 1). No significant differences were observed between the failed thrombolysis group and the control group $(\mathrm{P}>0.05)$.

\section{Discussion}

Stroke induces the body to produce an inflammatory response against brain tissue damage. Acute ischemic stroke, due to the interruption of regional cerebral blood flow, reperfusion and the destruction of the blood-brain barrier, causes
Table III. Correlation of NIHSS score at admission and inflammatory indicators.

\begin{tabular}{llcr}
\hline Inflammatory indicator & $\mathrm{N}$ & Spearman's rho & P-value \\
\hline $\begin{array}{l}\text { Body temperature } \\
\text { On admission }\end{array}$ & 62 & 0.115 & \\
Post-stroke day 1 & 62 & 0.122 & 0.250 \\
Post-stroke day 3 & 62 & 0.558 & $<0.195$ \\
Post-stroke day 5 & 62 & 0.152 & 0.145 \\
Post-stroke day 7 & 62 & 0.136 & 0.182 \\
Leukocyte & & & \\
On admission & 62 & 0.145 & 0.150 \\
Post-stroke day 1 & 62 & 0.232 & 0.035 \\
Post-stroke day 3 & 62 & 0.355 & 0.002 \\
Post-stroke day 5 & 62 & 0.150 & 0.166 \\
Post-stroke day 7 & 62 & 0.130 & 0.194 \\
hs-CRP & & & \\
On admission & 62 & 0.155 & 0.139 \\
Post-stroke day 1 & 62 & 0.162 & 0.110 \\
Post-stroke day 3 & 62 & 0.625 & $<0.001$ \\
Post-stroke day 5 & 62 & 0.457 & $<0.001$ \\
Post-stroke day 7 & 62 & 0.340 & 0.003 \\
\hline
\end{tabular}

NIHSS, National Institutes of Health Stroke Scale.

peripheral white blood cells to migrate and infiltrate into the brain, where they activate microglia, initiate inflammatory cascade reactions, release a series of inflammatory indicators and increase brain damage. This inflammatory response is 
Table IV. NIHSS scores and inflammatory indicators before and after treatment.

\begin{tabular}{|c|c|c|c|c|c|c|c|}
\hline Indicators & $\begin{array}{l}\text { Successful } \\
\text { thrombolysis } \\
\quad(n=36)\end{array}$ & $\begin{array}{l}\text { Failed } \\
\text { thrombolysis } \\
\quad(n=12)\end{array}$ & $\mathrm{t}^{\mathrm{a}}$ & P-value ${ }^{a}$ & $\begin{array}{c}\text { Control } \\
(n=14)\end{array}$ & $\mathrm{t}^{\mathrm{b}}$ & P-value ${ }^{b}$ \\
\hline \multicolumn{8}{|l|}{ NIHSS score } \\
\hline On admission & $10.0 \pm 4.8$ & $10.8 \pm 5.0$ & 0.495 & 0.623 & $9.8 \pm 4.5$ & 0.135 & 0.893 \\
\hline Post-stroke day 1 & $4.0 \pm 2.2$ & $8.7 \pm 3.4$ & 5.274 & $<0.001$ & $9.0 \pm 3.2$ & 6.323 & $<0.001$ \\
\hline Post-stroke day 7 & $2.2 \pm 1.6$ & $6.0 \pm 2.4$ & 6.252 & $<0.001$ & $7.0 \pm 2.1$ & 8.710 & $<0.001$ \\
\hline \multicolumn{8}{|c|}{ Body temperature $\left({ }^{\circ} \mathrm{C}\right)$} \\
\hline On admission & $36.4 \pm 0.5$ & $36.5 \pm 0.4$ & 0.628 & 0.533 & $36.6 \pm 0.5$ & 1.270 & 0.210 \\
\hline Post-stroke day 1 & $36.5 \pm 0.5$ & $36.7 \pm 0.6$ & 1.141 & 0.260 & $36.6 \pm 0.5$ & 0.635 & 0.528 \\
\hline Post-stroke day 3 & $36.5 \pm 0.7$ & $37.3 \pm 0.9$ & 3.189 & 0.003 & $37.4 \pm 0.9$ & 3.763 & $<0.001$ \\
\hline Post-stroke day 5 & $36.7 \pm 0.6$ & $36.8 \pm 0.5$ & 0.519 & 0.606 & $36.9 \pm 0.6$ & 1.058 & 0.295 \\
\hline Post-stroke day 7 & $36.5 \pm 0.6$ & $36.6 \pm 0.6$ & 0.500 & 0.619 & $36.5 \pm 0.5$ & 0.553 & 0.583 \\
\hline \multicolumn{8}{|l|}{ Leukocyte $\left(10^{9} / 1\right)$} \\
\hline On admission & $8.8 \pm 1.4$ & $8.7 \pm 2.0$ & 0.192 & 0.849 & $9.0 \pm 1.9$ & 0.406 & 0.687 \\
\hline Post-stroke day 1 & $10.9 \pm 1.8$ & $11.2 \pm 2.3$ & 0.466 & 0.643 & $11.0 \pm 2.0$ & 0.171 & 0.865 \\
\hline Post-stroke day 3 & $9.0 \pm 2.0$ & $12.6 \pm 2.5$ & 5.070 & $<0.001$ & $12.5 \pm 2.6$ & 5.100 & $<0.001$ \\
\hline Post-stroke day 5 & $8.8 \pm 1.2$ & $9.1 \pm 1.8$ & 0.658 & 0.514 & $9.3 \pm 2.0$ & 1.087 & 0.282 \\
\hline Post-stroke day 7 & $8.5 \pm 1.4$ & $8.7 \pm 1.5$ & 0.421 & 0.676 & $8.8 \pm 1.8$ & 0.627 & 0.534 \\
\hline \multicolumn{8}{|l|}{ hs-CRP (mg/l) } \\
\hline On admission & $9.0 \pm 6.4$ & $8.1 \pm 6.6$ & 0.419 & 0.677 & $7.9 \pm 7.0$ & 0.532 & 0.597 \\
\hline Post-stroke day 1 & $10.1 \pm 7.4$ & $14.3 \pm 8.7$ & 1.630 & 0.110 & $12.3 \pm 7.0$ & 0.958 & 0.343 \\
\hline Post-stroke day 3 & $32.8 \pm 9.9$ & $74.6 \pm 13.1$ & 11.663 & $<0.001$ & $80.4 \pm 11.6$ & 14.548 & $<0.001$ \\
\hline Post-stroke day 5 & $28.0 \pm 8.4$ & $50.8 \pm 10.6$ & 7.621 & $<0.001$ & $52.7 \pm 10.0$ & 8.849 & $<0.001$ \\
\hline Post-stroke day 7 & $23.5 \pm 7.6$ & $27.6 \pm 9.8$ & 1.504 & 0.139 & $28.2 \pm 8.8$ & 1.879 & 0.066 \\
\hline
\end{tabular}

${ }^{\mathrm{a} C}$ Comparison between the successful thrombolysis and failed thrombolysis groups; ${ }^{\mathrm{b}}$ Comparison between the successful thrombolysis and control groups. Successful thrombolysis group, after thrombolytic therapy, the reduction of NIHSS score within $24 \mathrm{~h}$ was $\geq 4$; failed thrombolysis group, after thrombolytic therapy, the reduction of NIHSS score within $24 \mathrm{~h}$ was $<4$; control group, no thrombolysis was performed and only conventional therapy was applied. NIHSS, National Institutes of Health Stroke Scale; hs-CRP, high-reactivity C-reactive protein.
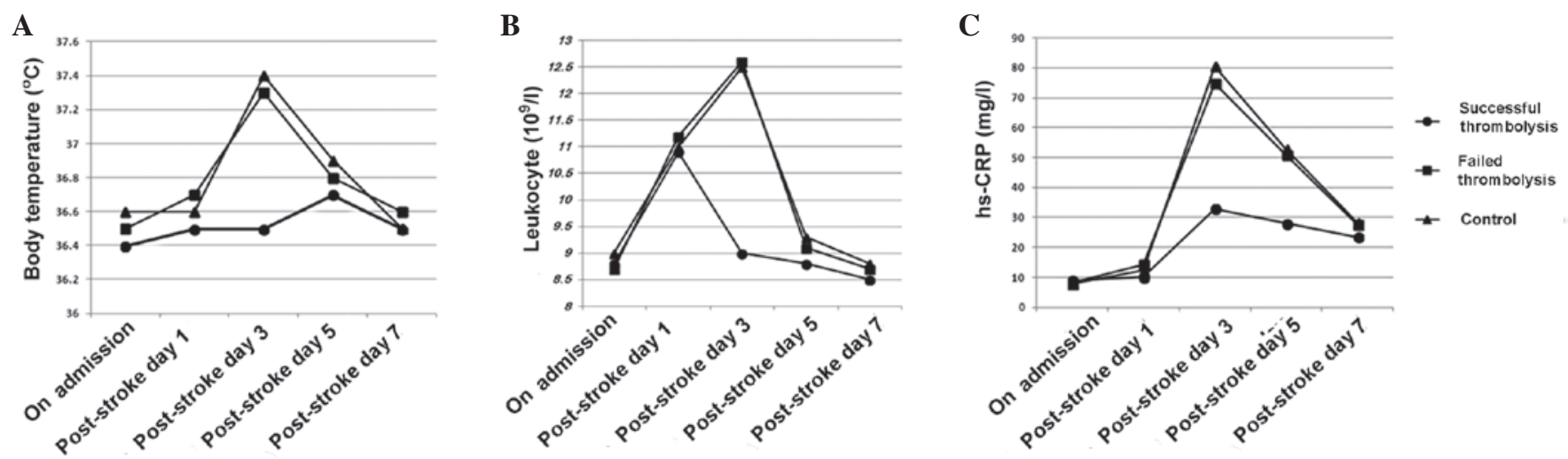

Figure 1. Changes of inflammatory indicators of the successful thrombolysis $(n=36)$, failed thrombolysis $(n=12)$ and control groups ( $=14)$ before and after the treatment. (A) The body temperature of the successful thrombolysis group was significantly lower than that in the other two groups on day 3 ( $<<0.005$ ), concurrently with $(\mathrm{B})$ a significant reduction in the number of peripheral blood leukocytes $(\mathrm{P}<0.001)$. (C) hs-CRP levels were significantly reduced in the successful thrombolysis groups on days 3 and $5(\mathrm{P}<0.001)$. hs-CRP, high-sensitivity $\mathrm{C}$-reactive protein.

not limited to the local brain tissue at the early stages, but is a general, non-specific and systemic inflammatory reaction. Biological markers, such as temperature and blood pressure, and physiologic parameters, such as peripheral blood leukocytes, CRP and interleukin-6, are important indicators of the systemic inflammatory response $(3,4)$. Post-stroke fever is a 
common clinical phenomenon, which might be not only the early systemic inflammatory response against necrotic brain tissue, but also caused by infection, deep vein thrombosis and other complications. Previous studies have shown that body temperature elevation is associated with the clinical severity and prognosis of stroke (12-14). Elevated body temperature is also a risk factor for the hemorrhagic transformation of acute ischemic stroke when recombinant tissue-type plasminogen activator treatment is not applied to patients (15). Some studies have found that the higher and sooner the body temperature increases in the acute phase of ischemic stroke, the more severe the brain damage is likely to be; however, this correlation exists only within the first $24 \mathrm{~h}$ of stroke $(16,17)$. Other studies have indicated that it is not admissional body temperature that is associated with adverse outcomes of stroke, but the temperature peak occurring a few days after the stroke (18-20). The present study revealed that the more serious the stroke and the higher the NIHSS score, the more the body temperature increased. The NIHSS score and body temperature showed a significant correlation on day 3 after admission, but no significant correlation on days 1 and 2 . The difference between these findings might be due to the fact that the studies were mostly retrospective analyses, which could not completely rule out concomitant infection. In addition, many factors are able to affect the body temperature measurement; oral or anal temperature readings would be more accurate.

In the acute stage of cerebral infarction, when the brain tissue is in a state of ischemia and hypoxia, stimulated leukocyte adhere to and aggregate on the vessel wall, releasing oxygen free radicals and other harmful substances, causing or aggravating tissue damage (1-3). Animal models have shown that a lack of white blood cells can reduce cerebral infarction volume, and thus reduce the inflammatory response (21). Therefore, many scholars consider that an increase in white blood cell counts is a risk factor for stroke, and is associated with poor prognosis $(22,23)$. The present study demonstrated that the higher the pre-treatment NIHSS score, the greater the number of peripheral blood leukocytes, particularly on days 1 and 3 after stroke. This result is also consistent with the aggregation phenomenon of lymphocytes in damaged brain tissues, which had been observed by Akopov et al (24).

CRP is an acute-phase reactant synthesized by liver cells and epithelial cells when stimulated by inflammatory factors. As an important inflammatory indicator, CRP is not only associated with systemic atherosclerosis and coronary heart disease, but also closely associated with the incidence, development and prognosis of cerebral infarction $(25,26)$. High levels of CRP have been found to be positively correlated with the severity and long-term mortality of ischemic stroke $(27,28)$. The present study found that the more serious the stroke on admission, as indicated by a higher NIHSS score, the higher the serum level of hs-CRP, particularly on days 3, 5 and 7 after the onset of the disease.

A series of pathophysiological changes occur following acute cerebral infarction. An ischemic penumbra forms; if the blood flow recovers rapidly, cell function can be restored to normal; if the ischemia increases, the range of infarction extends. Necrotic brain tissue would activate the inflammatory response through cells, body fluids and metabolic mechanisms, exhibited as fever, leukocytosis and increasing CRP levels. Previous studies have found a positive correlation between lesion size and changes in inflammatory indicators $(6,22)$. Thrombolytic therapy can facilitate the rapid recanalization of occlusive vasculature, restore blood flow and reduce ischemic area or infarct volume; therefore, it is regarded as the most important measure to restore blood flow. Recombinant tissue-type plasminogen activator (Alteplase) is the main thrombolytic drug currently used, with an effective therapeutic time window of $4.5 \mathrm{~h}$ (29). The present study showed that the clinical neurological functions of the patients undergoing successful intravenous thrombolytic therapy improved significantly, with a significant reduction of the inflammatory response. With regard to the detailed clinical presentation, compared with the failed thrombolytic treatment and control groups, the patients in the successful thrombolytic group exhibited NIHSS neurological deficit scores that were significantly reduced on days 1 and 7 after treatment. In addition, they exhibited a significant reduction in body temperature on day 3 , accompanied by a significant reduction in the number of peripheral blood leukocytes, and a significant reduction in hs-CRP levels on days 3 and 5. These results are consistent with previous studies (30-33), and suggest that the systemic inflammatory response following acute cerebral infarction arises mainly because of ischemic injury of local brain tissue, rather than cryptogenic infection. and that successful thrombolytic therapy could reduce the necrosis of brain tissue, reduce inflammation and induce tissue repair.

In summary, the present study observed that acute ischemic stroke induces a systemic inflammatory response due to the necrosis of brain tissue, causing increases in peripheral inflammatory indicators (body temperature, peripheral blood leukocyte counts and hs-CRP levels). Changes in the inflammatory indicators are associated with the severity of stroke. Ultra-early and effective thrombolytic therapy can significantly reduce the systemic inflammatory response and improve nerve function.

\section{References}

1. Zierath D, Thullbery M, Hadwin J, Gee JM, Savos A, Kalil A and Becker KJ: CNS immune responses following experimental stroke. Neurocrit Care 12: 274-284, 2010.

2. Nakase T, Yamazaki T, Ogura N, Suzuki A and Nagata K: The impact of inflammation on the pathogenesis and prognosis of ischemic stroke. J Neurol Sci 271: 104-109, 2008.

3. Wang Q, Tang XN and Yenari MA: The inflammatory response in stroke. J Neuroimmunol 184: 53-68, 2007.

4. Shenhar-Tsarfaty S, Assayag EB, Bova I, Shopin L, Berliner S, Shapira I and Bornstein NM: Early signaling of inflammation in acute ischemic stroke: Clinical and rheological implications. Thromb Res 122: 167-173, 2008.

5. McColl BW, Allan SM and Rothwell NJ: Systemic inflammation and stroke: Aetiology, pathology and targets for therapy. Biochem Soc Trans 35: 1163-1165, 2007.

6. Sotgiu S, Zanda B, Marchetti B, Fois ML, Arru G, Pes GM, Salaris FS, Arru A, Pirisi A and Rosati G: Inflammatory biomarkers in blood of patients with acute brain ischemia. Eur J Neurol 13: 505-513, 2006.

7. Harms H, Prass K, Meisel C, Klehmet J, Rogge W, Drenckhahn C, Göhler J, Bereswill S, Göbel U, Wernecke KD, et al: Preventive antibacterial therapy in acute ischemic stroke: A randomized controlled trial. PLoS One 3: e2158, 2008.

8. Schwarz S, Al-Shajlawi F, Sick C, Meairs S and Hennerici MG: Effects of prophylactic antibiotic therapy with mezlocillin plus sulbactam on the incidence and height of fever after severe acute ischemic stroke: The Mannheim Infection in Stroke Study (MISS). Stroke 39: 1220-1227, 2008. 
9. Ad Hoc Committee representing the National Stroke Foundation and the Stroke Society of Australasia: The implementation of intravenous tissue plasminogen activator in acute ischaemic stroke - a scientific position statement from the National Stroke Foundation and the Stroke Society of Australasia. Intern Med J 39: 317-324, 2009.

10. Adams HP Jr, del Zoppo G, Alberts MJ, Bhatt DL, Brass L, Furlan A, Grubb RL, Higashida RT, Jauch EC, Kidwell C, et al: Guidelines for the early management of adults with ischaemic stroke: A guideline from the American Heart Association/American Stroke Association Stroke Council, Clinical Cardiology Council, Cardiovascular Radiology and Intervention Council and the Atherosclerotic Peripheral Vascular Disease and Quality of Care Outcomes in Research Interdisciplinary Working Groups: The American Academy of Neurology affirms the value of this guideline as an educational tool for neurologists. Stroke 38: 1655-1711, 2007.

11. Adams HP Jr, Bendixen BH, Kappelle LJ, Biller J, Love BB, Gordon DL and Marsh EE III: Classification of subtype of acute ischemic stroke. Definitions for use in a multicenter clinical trial. TOAST. Trial of Org 10172 in Acute Stroke Treatment. Stroke 24: 35-41, 1993.

12. Naess H, Idicula T, Lagallo N, Brogger J, Waje-Andreassen U and Thomassen L: Inverse relationship of baseline body temperature and outcome between ischemic stroke patients treated and not treated with thrombolysis: The Bergen stroke study. Acta Neurol Scand 122: 414-417, 2010.

13. Saini M, Saqqur M, Kamruzzaman A, Lees KR and Shuaib A; VISTA Investigators: Effect of hyperthermia on prognosis after acute ischemic stroke. Stroke 40:3051-3059, 2009.

14. Greer DM, Funk SE, Reaven NL, Ouzounelli M and Uman GC: Impact of fever on outcome in patients with stroke and neurologic injury: A comprehensive meta-analysis. Stroke 39: 3029-3035, 2008.

15. Leira R, Sobrino T, Blanco M, Campos F, Rodríguez-Yáñez M, Castellanos M, Moldes O, Millán M, Dávalos A and Castillo J: A higher body temperature is associated with haemorrhagic transformation in patients with acute stroke untreated with recombinant tissue-type plasminogen activator (rtPA). Clin Sci (Lond) 122: 113-119, 2012.

16. Wang Y, Lim LL, Levi C, Heller RF and Fisher J: Influence of admission body temperature on stroke mortality. Stroke 31: 404-409, 2000

17. Kammersgaard LP, Jørgensen HS, Rungby JA, Reith J, Nakayama H, Weber UJ, Houth J and Olsen TS: Admission body temperature predicts long-term mortality after acute stroke: The Copenhagen Stroke Study. Stroke 33: 1759-1762, 2002.

18. Karaszewski B, Thomas RG, Dennis MS and Wardlaw JM: Temporal profile of body temperature in acute ischemic stroke: Relation to stroke severity and outcome. BMC Neurol 12: 123, 2012.

19. den Hertog HM, van der Worp HB, van Gemert HM, Algra A Kappelle LJ, van Gijn J, Koudstaal PJ and Dippel DW: An early rise in body temperature is related to unfavorable outcome after stroke: Data from the PAIS study. J Neurol 258: 302-307, 2011.

20. Leira R, Rodríguez-Yáñez M, Castellanos M, Blanco M, Nombela F, Sobrino T, Lizasoain I, Dávalos A and Castillo J: Hyperthermia is a surrogate marker of inflammation-mediated cause of brain damage in acute ischaemic stroke. J Intern Med 260: 343-349, 2006.
21. Hurn PD, Subramanian S, Parker SM, Afentoulis ME, Kaler LJ, Vandenbark AA and Offner H: T- and B-cell-deficient mice with experimental stroke have reduced lesion size and inflammation. J Cereb Blood Flow Metab 27: 1798-1805, 2007.

22. Smith CJ, Emsley HC, Gavin CM, Georgiou RF, Vail A, Barberan EM, del Zoppo GJ, Hallenbeck JM, Rothwell NJ, Hopkins SJ and Tyrrell PJ: Peak plasma interleukin-6 and other peripheral markers of inflammation in the first week of ischaemic stroke correlate with brain infarct volume, stroke severity and long-term outcome. BMC Neurol 4: 2, 2004.

23. Christensen $\mathrm{H}$ and Boysen $\mathrm{G}$ : C-reactive protein and white blood cell count increases in the first $24 \mathrm{~h}$ after acute stroke. Cerebrovasc Dis 18: 214-219, 2004.

24. Akopov SE, Simonian NA and Grigorian GS: Dynamics of polymorphonuclear leukocyte accumulation in acute cerebral infarction and their correlation with brain tissue damage. Stroke 27: 1739-1743, 1996.

25. Elias-Smale SE, Kardys I, Oudkerk M, Hofman A and Witteman JC: C-reactive protein is related to extent and progression of coronary and extra-coronary atherosclerosis; results from the Rotterdam study. Atherosclerosis 195: e195-e202, 2007.

26. Ridker PM, Danielson E, Fonseca FA, Genest J, Gotto AM Jr, Kastelein JJ, Koenig W, Libby P, Lorenzatti AJ, MacFadyen JG, et al: Rosuvastatin to prevent vascular events in men and women with elevated C-reactive protein. N Engl J Med 359: 2195-2207, 2008.

27. Idicula TT, Brogger J, Naess H, Waje-Andreassen U and Thomassen L: Admission C-reactive protein after acute ischemic stroke is associated with stroke severity and mortality: The 'Bergen stroke study'. BMC Neurol 9: 18, 2009.

28. den Hertog HM, van Rossum JA, van der Worp HB, van Gemert HM, de Jonge R, Koudstaal PJ and Dippel DW; PAIS investigators: C-reactive protein in the very early phase of acute ischemic stroke: Association with poor outcome and death. J Neurol 256: 2003-2008, 2009.

29. Hacke W, Kaste M, Bluhmki E, Brozman M, Dávalos A, Guidetti D, Larrue V, Lees KR, Medeghri Z, Machnig T, et al: Thrombolysis with alteplase 3 to $4.5 \mathrm{~h}$ after acute ischemic stroke. N Engl J Med 359: 1317-1329, 2008.

30. Audebert HJ, Rott MM, Eck T and Haberl RL: Systemic inflammatory response depends on initial stroke severity but is attenuated by successful thrombolysis. Stroke 35: 2128-2133, 2004.

31. Hemmen TM, Raman R, Guluma KZ, Meyer BC, Gomes JA, Cruz-Flores S, Wijman CA, Rapp KS, Grotta JC and Lyden PD; ICTuS-L Investigators: Intravenous thrombolysis plus hypothermia for acute treatment of ischemic stroke (ICTuS-L): Final results. Stroke 41: 2265-2270, 2010.

32. Idicula TT, Waje-Andreassen U, Brogger J, Naess H, Lundstadsveen MT and Thomassen L: The effect of physiologic derangement in patients with stroke treated with thrombolysis. J Stroke Cerebrovasc Dis 17: 141-146, 2008.

33. Millan M, Grau L, Castellanos M, Rodríguez-Yáñez M, Arenillas JF, Nombela F, Pérez de la Ossa N,López-Manzanares L, Serena J, Castillo J and Dávalos A: Body temperature and response to thrombolytic therapy in acute ischaemic stroke. Eur J Neurol 15: 1384-1389, 2008. 